\title{
A Comparative Study of Techniques for Modeling the Spatiotemporal Distribution of Heat and Moisture Fluxes at Different Agroecosystems in Brazil
}

\author{
Antônio Heriberto de Castro Teixeira, Fernando Braz Tangerino Hernandez, \\ H. L. Lopes, Morris Scherer-Warren, and Luís Henrique Bassoi
}

\section{CONTENTS}

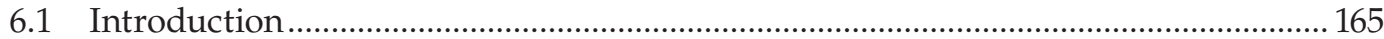

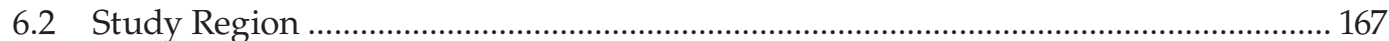

6.3 Modeling the Energy Balance on a Large Scale ........................................................ 168

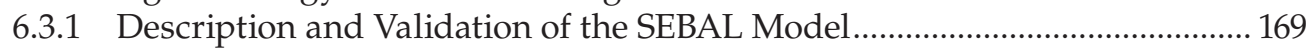

6.3.2 Description and Validation of the SAFER Model............................................. 174

6.4 Comparison between SEBAL and SAFER Methods ................................................. 177

6.5 Retrieving the Energy Balance Components at Different Spatial and Temporal

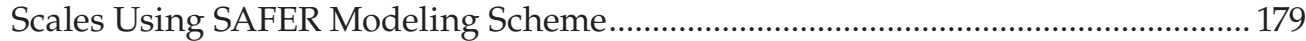

6.5.1 Evapotranspiration at the Municipality Scale ................................................ 180

6.5.1.1 Monthly Evapotranspiration from the Petrolina Municipality........ 180

6.5.1.2 Daily and Annual ET from the Juazeiro Municipality...................... 181

6.5.2 Energy Balance at the Irrigation Scheme Scale .............................................. 182

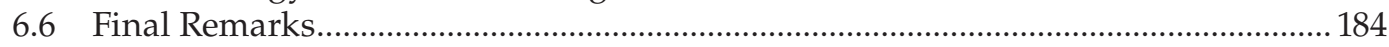

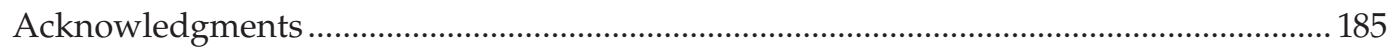

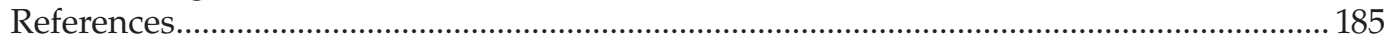

\subsection{Introduction}

The difficulties to measure the energy fluxes from mixed agroecosystems by field experiments make the use of remote sensing by satellite images a valuable application and its use for this purpose has already been demonstrated in different climate regions (Tang et al. 2009; Teixeira 2010; Miralles et al. 2011; Anderson et al. 2012; Pôças et al. 2013). Remote sensing is a suitable way for determining and mapping the spatial and temporal structure of the water and energy balance components. Hydrological models can be too complex and costly to be used for this purpose because of unavailability of datasets in different hydrological uniform subareas (Majumdar et al. 2007).

Several remote sensing algorithms have been developed, being based largely on the energy balance theories, highlighted by some advantages and shortcomings. The Surface Energy Balance Algorithm for Land (SEBAL) (Bastiaanssen et al. 1998), the Simplified Surface Energy Balance Index (S-SEBI) (Roerink et al. 2000), and the Surface Energy Balance System (SEBS) (Su 2002) are some examples. Those techniques can be applied to 
various agroecosystems without the need of crop classification, which is difficult to do in mixed agroecosystems.

Among others, Kustas et al. (2006) underline that the remote surface temperature and vegetation cover must be at high enough resolutions where different land surface conditions can be distinguished, with the validation of flux distributions predicted by modeling being important. Procedures for the validation of energy fluxes derived from remote sensing involve intercomparisons among methods (Liu et al. 2003; Su et al. 2005; Tasumi and Allen 2007; Teixeira 2010), with satellite and field energy balance measurements.

The disadvantage of many remote sensing energy balance methods, such as SEBAL and SEBS, is the need to identify hydrological extreme conditions, which is not required for the Two-Source Model (TSM) (Kustas and Norman 1999), dual-temperature difference (DTD) (Norman et al. 2000), and the Disaggregated Atmosphere Land Exchange Inverse (DisALEXI) model (Norman et al. 2003). The aerodynamic resistance-surface energy balance (RSEB) approach (Kalma and Jupp 1990) fails because small errors in the radiative temperature translate into large inaccuracies in the sensible heat flux $(H)$ and then into estimates of actual evapotranspiration (ET).

The other problem in relation to the practical applicability of the remote sensing energy balance models, aiming at the end users, is the need of background knowledge in radiation physics involved in the description of these algorithms. For example, the suitability of applying the Penman-Monteith (PM) equation by the surface conductance algorithm has been shown by using remotely sensed vegetation indices, such as the normalized difference vegetation index (NDVI), together with weather data (Cleugh et al. 2007). Yet, perhaps the strongest advantages of the PM equation include the method applicability and the low sensitivity to input data and parameters. Its use is also highlighted by the model named Mapping Evapotranspiration with High Resolution and Internalized Calibration (METRIC) (Allen et al. 2007), which applies the ratio of ET to reference evapotranspiration (ET0) for extrapolating satellite overpass ET values to larger timescales.

Although the worldwide known SEBAL algorithm had been calibrated and validated with field radiation and energy balance measurements, showing satisfactory performances in the Brazilian semiarid region (Teixeira et al. 2009a,b), the major difficulty in its applicability for deriving estimates for the whole year is the assumption of zero latent heat flux $(\lambda E)$ for dry pixels. This is because during the rainy season, the mixed ecosystems of irrigated crops and natural vegetation are homogenously wet with the whole region presenting high ET rates.

Considering the simplicity of application and the absence of the need of neither crop classification nor extreme conditions, a model for ET acquirements based on the modeled ratio ET/ET0, called Simple Algorithm For Evapotranspiration Retrieving (SAFER), was recently developed in the semiarid conditions of Brazil, which has already been validated with field data from four flux stations involving irrigated crops and natural vegetation (Teixeira 2012a). A second biophysical model was also built for the same region allowing the acquirement of the surface resistance to the water fluxes $\left(r_{s}\right)$, which, when establishing threshold values for $r_{s}$ is useful for classifying irrigated crops and natural vegetation (Teixeira et al. 2012b).

These two modeling approaches when used together with satellites having different spatial and temporal resolutions and agrometeorological stations can be appropriate for implementation allowing one to derive ET on large scales. In addition, together with the net radiation $\left(R_{n}\right)$ acquired by the slob equation (Bruin and Stricker 2000; Teixeira et al. 2008, 2009a), the SAFER and $r_{s}$ models allow the quantification of $H$ daily values from different agroecosystems. 
The SAFER algorithm has the additional advantage of the possibility for using daily weather data from either conventional or automatic agrometeorological stations. This is an important characteristic because it allows a historical evaluation of the energy balance components on a large scale, as data from automatic sensors are results from relatively recent advances on instrumental technology.

Given the recent development of SAFER, not many comparative studies have been performed so far, evaluating its performance, even more in a Brazilian environment. Hernandez et al. (in press) recently compared SEBAL and SAFER algorithms with the traditional Food and Agricultural Organization (FAO) crop coefficient $\left(K_{c}\right)$ methodology (Allen et al. 1998). The remote sensing methods and water managements in corn, bean, and sugar cane growing under center pivot sprinkler irrigation systems were evaluated in the northwestern part of São Paulo State, Brazil. They concluded that ET results from both algorithms were higher than the water applied with these overestimations being mainly related to errors on crop stages evaluation by the irrigation manager. However, the authors pointed out that the SAFER algorithm performed better than SEBAL when these crops presented lower leaf areas, partially covering the soil beneath the canopies.

The objective of this chapter is two-fold: first, to perform a comparative study of SAFER and SEBAL evaluating their ability in modeling the spatiotemporal distribution of ET at different crops in Brazil using the FAO method as reference corresponding estimates; and second, to demonstrate SAFER's applicability in subsidizing the monitoring of land use effects on the energy exchange processes by using field and satellite measurements in the Brazilian semiarid environment.

As a result, this chapter is structured as follows: following the introduction, the study region, datasets, and the steps for modeling are described; one of the first comparisons between SAFER and SEBAL is then made available, comparing estimates by these two modeling approaches against corresponding estimates by the traditional FAO methodology; next, results from case studies are furnished, covering application of both SAFER and SEBAL methods with satellite images, in some irrigation crops and natural vegetation at different spatial and temporal scales in the Brazilian semiarid region.

\subsection{Study Region}

Figure 6.1 shows the locations of Petrolina (PE) and Juazeiro (BA) municipalities, the Nilo Coelho scheme, and the agrometeorological stations together with pictures of the main vegetation types involved in the semiarid region of the Brazilian Northeast.

In the semiarid region of Brazil, situated in the northeastern part of the country, disturbed currents of south, north, east, and west influence the climatology. Excluding the places of high altitude, all areas present annual averaged air temperatures higher than $24^{\circ} \mathrm{C}$, even bigger than $26^{\circ} \mathrm{C}$ in the depressions at 200 to $250 \mathrm{~m}$ of altitude. The average maximum air temperature is $33^{\circ} \mathrm{C}$ and the average minimum is $19^{\circ} \mathrm{C}$. The mean monthly values are in the range from $17^{\circ} \mathrm{C}$ to $29^{\circ} \mathrm{C}$. The rainy period is concentrated between January and April, with the peak happening in March (Teixeira 2009). In the Nilo Coelho irrigation scheme the lowest irrigated area occurs in February, while the highest one is in July (Bastiaanssen et al. 2001).

The main commercial crops in the Brazilian semiarid region are mango orchards and vineyards surrounded by natural vegetation named Caatinga (Figure 6.1). Mango trees 


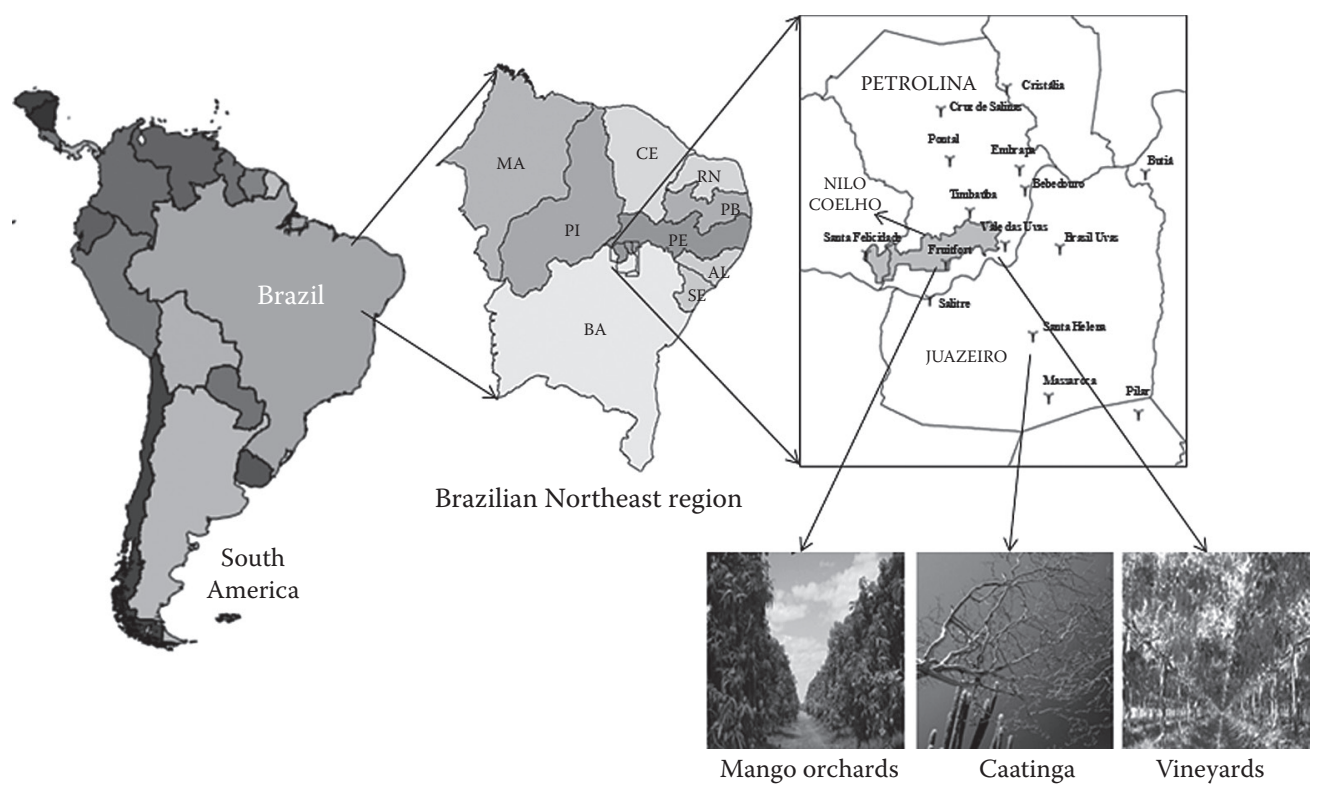

FIGURE 6.1

Location of the Brazilian semiarid study region with highlights for Petrolina (PE) and Juazeiro (BA) municipalities, Nilo Coelho irrigation scheme, the agrometeorological stations, and the main agroecosystems.

may have flowering and fruit set regularly every year. The vineyards growing under tropical warm conditions exhibit continuous and accelerated physiological processes, differently from those growing in temperate climates. Caatinga species are defined by bush aspects possessing small leaves and thorns, distributed in an irregular way, with soil patches of bare soil and clumps of vegetation interspersed (Teixeira 2009a,b).

The 15 agrometeorological stations showed in the right side of Figure 6.1 are inside irrigated and natural vegetation areas. They are equipped with radiometers to measure the incident solar radiation (RS $\downarrow$ ); sensors for measuring air temperature $\left(T_{a}\right)$ and relative humidity $(\mathrm{RH})$; and wind speed $(u)$, allowing the calculation of ET0 by the FAO PenmanMonteith method (Allen et al. 1998). Grids of RS $\downarrow, T_{a}$, and $\mathrm{ET}_{0}$ were used together with remote sensing retrieving parameters from MODIS and Landsat satellite images during the steps for modeling the energy balance components at different spatiotemporal scales.

\subsection{Modeling the Energy Balance on a Large Scale}

Among the satellite-based ET models developed during recent years the SEBAL algorithm has been widely used for heterogeneous surfaces. This model involves the spatial variability of the most agrometeorological variables and can be applied to various ecosystems. However, aiming simplicity of application, the SAFER algorithm was recently developed, having the advantages in terms of applicability in relation to SEBAL already commented in Section 6.1. In the following sections, the principles and descriptions of both models are done to facilitate understanding further comparisons and analyses. 


\subsubsection{Description and Validation of the SEBAL Model}

In this chapter, applications of SEBAL algorithm are analyzed with Landsat 5 images only. SEBAL requires spatially distributed, visible, near-infrared, and thermal infrared data together with weather data. The algorithm computes $R_{n}, H$, and soil heat flux $(G)$ for every pixel of a satellite image at the overpass time and $\lambda E$ is acquired as a residual in energy balance:

$$
R_{n}-\lambda E-H-G=0
$$

where all terms are expressed in $\mathrm{W} \mathrm{m}^{-2}$.

During the first step of SEBAL, the radiation balance is obtained by

$$
R_{n}=\mathrm{RS} \downarrow-\alpha_{0} \mathrm{RS} \downarrow-\mathrm{RL} \uparrow+\mathrm{RL} \downarrow
$$

where $R S \downarrow$ is in $\mathrm{W} \mathrm{m}^{-2}, \alpha_{0}$ is the surface albedo, and RL $\uparrow$ and $\mathrm{RL} \downarrow$ are the outgoing and the incoming longwave radiation $\left(\mathrm{W} \mathrm{m}^{-2}\right)$, respectively.

For Landsat 5 the spectral radiance for each band $\left(L_{b}\right)$ is computed as

$$
L_{b}=\left[\frac{L_{\max }-L_{\min }}{\mathrm{QCAL}_{\max }-\mathrm{QCAL}_{\min }}\right]\left(\mathrm{DN}-\mathrm{QCAL}_{\text {min }}\right)+L_{\text {min }}
$$

where DN is the digital number of each pixel, $L_{\mathrm{MAX}}$ and $L_{\mathrm{MIN}}$ are calibration constants, $\mathrm{QCAL}_{\max }$ and $\mathrm{QCAL}_{\min }$ are the highest and lowest range of values for rescaled radiance in $\mathrm{DN}$, respectively. The unit for $L_{b}$ is $\mathrm{W} \mathrm{m}^{-2} \mathrm{sr}^{-1} \mu \mathrm{m}^{-1}$ and $\mathrm{QCAL}_{\max }=255$ and $\mathrm{QCAL}_{\min }=0$.

In the radiation balance, the net shortwave radiation available at the Earth's surface depends on RS $\downarrow$ and $\alpha_{0}$. The second parameter is calculated from satellite-measured spectral radiances for each narrowband, followed by mathematical expressions for spectral integration and atmospheric corrections.

The bands 1 to 5 and 7 with pixel size of $30 \times 30 \mathrm{~m}$ from Landsat 5 provide data for the visible and near-infrared bands for the broadband planetary albedo $\left(\alpha_{p}\right)$ calculations. For each satellite band $\left(\alpha_{p_{b}}\right)$ it is calculated as

$$
\alpha_{p_{b}}=\frac{L_{b} \pi d^{2}}{R_{a_{b}} \cos \varphi}
$$

where $d$ is the relative Earth-Sun distance, $R_{a_{b}}$ is the mean solar irradiance at the top of the atmosphere for each band $\mathrm{b}\left(\mathrm{W} \mathrm{m}^{-2} \mu \mathrm{m}^{-1}\right)$, and $\varphi$ is the solar zenith angle. $\alpha_{p}$ is calculated as the total sum of the different narrowband $\alpha_{p_{b}}$ values according to weights for each band $\left(w_{b}\right)$.

$$
\alpha_{p}=\sum w_{b} \alpha_{p_{b}}
$$

The weights for the different bands in Equation 6.5 are computed as the ratio of the amount of incoming shortwave radiation from the Sun in a particular band and the sum of incoming shortwave radiation for all the bands at the top of the atmosphere. 
The atmosphere disturbs the signal reaching the satellite sensor. The satellite registered radiances are therefore affected by the atmospheric interaction in the radiative transfer path. Part of RS $\downarrow$ is scattered back to the satellite before it reaches the Earth surface. Combination of field measurements of $\alpha_{0}$ (Teixeira et al. 2008) with Landsat calculations of $\alpha_{p}$ resulted in a linear relationship for correcting all atmospheric disturbances:

$$
\alpha_{0}=a \alpha_{p}+b
$$

where $a=0.61$ and $b=0.08$ are the satellite overpass regression coefficients found in the Brazilian semiarid conditions for the period of the images (Teixeira et al. 2009a; Teixeira 2010).

The Landsat overpass measurements yielded instantaneous values of surface albedo $\left(\alpha_{0_{\text {inst }}}\right)$ that were systematically lower than those for $24 \mathrm{~h}\left(\alpha_{0_{24}}\right)$. Hence a second regression equation was applied to retrieve the daily from instantaneous values

$$
\alpha_{0_{\text {inst }}}=a \alpha_{0_{24}}+b
$$

where $a=1.02$ and $b=0.01$ are the regression coefficients found in the Brazilian semiarid region for the period of the satellite images (Teixeira et al. 2009a; Teixeira 2010).

Equation 6.7 has been considered in the computations of the 24-h values of $R_{n}$ required for the determination of daily $\lambda E$ with the SEBAL model.

The spectral radiance of the thermal region of Landsat 5 (band 6), with a pixel size of $120 \times 120 \mathrm{~m}$, is converted into a radiation temperature applicable at the top of the atmosphere $\left(T_{\text {sat }}\right)$ by inversion of Plank's law in the $10.4-12.5 \mu \mathrm{m}$ bandwidth:

$$
T_{\text {sat }}=\frac{K_{2}}{\ln \left(\frac{K_{1}}{L_{b_{\text {(Thermal })}}}+1\right)}
$$

where $L_{b \text { (Thermal) }}$ for Landsat 5 is the uncorrected spectral radiance for band 6 from the land surface and the conversion coefficients $K_{1}$ and $K_{2}$ are, respectively, $607.76 \mathrm{~W} \mathrm{~m}^{-2} \mathrm{sr}^{-1} \mu \mathrm{m}^{-1}$ and $1260.56 \mathrm{~K}$ for Landsat 5 (Schneider and Mauser 1996).

From field energy balance experiments (Teixeira et al. 2008), the vertical temperature difference $(\Delta T)$ between two heights was derived using data of $H, T_{a}$ above the canopies, and the aerodynamic resistance $r_{a}$ (Smith et al. 1989).

$$
\Delta T=\frac{H r_{a}}{\rho_{a} c_{p}}
$$

where $\rho_{\mathrm{a}}\left(\mathrm{kg} \mathrm{m}^{-3}\right)$ and $c_{p}\left(\mathrm{~J} \mathrm{~kg}^{-1} \mathrm{~K}^{-1}\right)$ are the air density and air specific heat at constant pressure, respectively.

Experiments have demonstrated that, other than a thin surface such as bare soil or a short canopy, a difference of several degrees can be observed between radiometric and aerodynamic surface temperature (Troufleau et al. 1997). The thermal radiation measured by satellite sensors thus need to be corrected for both atmosphere emission and the difference between radiometric and aerodynamic surface temperature. To correct these 
conjugated effects, the field results from Equation 6.9 were used to fit a linear relationship between $T_{0}\left(T_{0}=T_{a}+\Delta T\right)$ and $T_{\text {sat }}$ :

$$
T_{0}=a T_{\text {sat }}+b
$$

where the coefficients $a=1.07$ and $b=-20.17$ were found for the Brazilian semiarid region for the period of the Landsat satellite images used (Teixeira et al. 2009a; Teixeira 2010).

It is realized that a physically based atmospheric correction would include transmittance and reflectance of spectral radiances (e.g., Schmugge et al. 1998), but for practical reasons, Equations 6.6 and 6.10 are doable.

The NDVI, which is an indicator related to the land cover, is obtained as

$$
\mathrm{NDVI}=\frac{\alpha_{p_{(\mathrm{NIR})}}-\alpha_{p_{(\mathrm{RED})}}}{\alpha_{p_{(\mathrm{NIR})}}+\alpha_{p_{(\mathrm{RED})}}}
$$

where $\alpha_{p_{\text {(NIR })}}$ and $\alpha_{p_{\text {(RED })}}$ represent the planetary albedo over the ranges of wavelengths in the near-infrared (NIR) and red (RED) regions of the solar spectrum. For Landsat images these regions correspond to bands 4 and 3, respectively.

RS $\downarrow$ was measured in the agrometeorological stations from Figure 6.1. RL $\downarrow$ can be calculated by using the Stefan-Boltzmann equation with an empirically determined atmospheric emissivity $\left(\varepsilon_{\mathrm{a}}\right)$ and $T_{a}$ data (Allen et al. 1998). RL $\uparrow$ can also be obtained through the Stefan-Boltzmann equation with an empirically determined surface emissivity $\left(\varepsilon_{0}\right)$ and $T_{0}$ acquired by the satellite after atmospheric correction (Teixeira et al. 2009a; Teixeira 2010).

The Stefan-Boltzmann equation applied for the satellite overpass time to calculate RL $\downarrow$ is

$$
\mathrm{RL} \downarrow=\varepsilon_{a} \sigma T_{a}^{4}
$$

where $\sigma\left(5.67 \times 10^{-8} \mathrm{~W} \mathrm{~m}^{-2} \mathrm{~K}^{-4}\right)$ is the Stefan-Boltzmann constant and $T_{a}$ is in $\mathrm{K}$.

The atmospheric emissivity was calculated with the following relation:

$$
\varepsilon_{a}=a\left(-\ln \tau_{\mathrm{s}}\right)^{b}
$$

where $\tau_{\mathrm{s}}$ is the shortwave atmospheric transmissivity and the regression coefficients were $a=0.942$ and $b=0.103$ for the satellite overpass time in the semiarid region of Brazil (Teixeira et al. 2009a; Teixeira 2010). Equation 6.13 was thereafter applied to satellite images to obtain the large-scale incoming longwave radiation.

Field values of RL $\uparrow$ - jointly with estimates of $T_{0}$ - gave the opportunity to quantify the thermal infrared emissivity $\left(\varepsilon_{0}\right)$. The field values of $\varepsilon_{0}$ (Teixeira et al. 2008) were correlated with NDVI from satellite images:

$$
\varepsilon_{0}=a \operatorname{lnNDVI}+b
$$

where $a$ and $b$ are regression coefficients being 0.06 and 1.00, respectively, for the Brazilian semiarid conditions (Teixeira et al. 2009a; Teixeira 2010).

The values of $\varepsilon_{0}$ were used for estimation of RL $\uparrow$ in the regional radiation balance by applying Equation 6.12 replacing $T_{a}$ and $\varepsilon_{a}$ by $T_{0}$ and $\varepsilon_{0}$. 
The second step of the SEBAL algorithm is to compute the large-scale values of $G$ and $H$. Satellite overpass $G$ values are calculated by modeling the ratio $G / R_{n}$, while those for $H$ are obtained throughout the near-surface temperature gradients $(\Delta T)$. The first value for friction velocity $\left(u_{*}\right)$ is computed for neutral atmospheric stability, using weather data from agrometeorological stations. The near-surface wind speed $(u)$ is converted to a value at the blending height, where the effects from the land surface roughness can be neglected. A height of $200 \mathrm{~m}$ can be considered $\left(\mathrm{u}_{200}\right)$. The first estimate of $u_{*}$ is used-conjunctively with surface roughness estimates-to infer the large-scale values of $r_{a}$. Corrections for atmosphere stability are obtained iteratively for each pixel. A series of iterations is required to determine new corrected values of $u_{*}$ and $r_{a}$ before obtaining numerical stability.

SEBAL computes $\Delta T$ by assuming its linear relationship with $T_{0}$, and the coefficients of this relationship are acquired by following an internal calibration procedure (Allen et al. 2007; Teixeira et al. 2009a). The algorithm considers two "anchor" pixels at which a value for $H$ can be estimated on the basis of a priori knowledge of the fluxes over dryland (hot pixel) and wet terrain (cold pixel). The sensible heat fluxes in these sites $\left(H_{\text {hot }}\right.$ and $\left.H_{\text {cold }}\right)$ can be calculated applying Equation 6.1.

In the following the essential SEBAL equations are shown together with techniques for local calibrations and validations described by Teixeira et al. (2009a).

Field values of roughness length for momentum transfer $\left(z_{0 m}\right)$ in natural vegetation and irrigated crops (Teixeira et al. 2008) were used to estimate $z_{0 m}$ from remote sensing parameters:

$$
z_{0 m}=\exp \left[\left(a \frac{\mathrm{NDVI}}{\alpha_{0}}\right)+b\right]
$$

where $z_{0 m}$ is given in $\mathrm{m}$ and the regression coefficients for the semiarid conditions of Brazil were $a=0.26 \mathrm{~m}$ and $b=-2.21$ (Teixeira et al. 2009a).

Field measurements of $G$ and $R_{n}$ were used together with satellite measurements of $T_{0}, \alpha_{0}$, and NDVI to calibrate the following multiple regression equation (Bastiaanssen et al. 1998):

$$
\frac{G}{R_{n}}=T_{0}\left(a \alpha_{0}+b\right)\left(1-0.98 \mathrm{NDVI}^{4}\right)
$$

where $T_{0}$ is in degrees Celsius and $a$ and $b$ are regression coefficients, which were $a=$ $-0.11^{\circ} \mathrm{C}^{-1}, b=0.02$, respectively, for the Brazilian semiarid conditions (Teixeira et al. 2009a).

To compute $H$, the following equation is applied:

$$
H=\frac{\rho_{a} c_{p} \Delta T}{r_{a}}
$$

$\Delta T$ for each pixel is given as $\left(T_{1}-T_{2}\right)$, the temperature difference between two heights $\left(z_{1}\right.$ and $\left.z_{2}\right)$, and its regionalization occurs by assuming a linear relationship with $T_{0}$ :

$$
\Delta T=a T_{0}+b
$$

where $a$ and $b$ are the fitting coefficients. 
Originally, at the cold pixel $H$ is neglected and $\lambda E$ is calculated as a residual in Equation 6.1, while in the hot pixel $\lambda E$ is assumed to be zero (Bastiaanssen et al. 1998). Teixeira et al. (2009a) did not neglect any energy fluxes in both wet pixel (mango orchard) and natural Caatinga (dry pixel). Mango orchard was chosen because it represents the largest irrigated area in the study region, while Caatinga is the driest natural vegetation, where in some periods of the year, ET is close to zero. Instead, they used the specific values for the ratio of ET to $\mathrm{ET}_{0}$ in Equation 6.1 to estimate these fluxes in those pixels. The $H$ values under these extreme conditions were used to infer $\Delta T$ applying Equation 6.17 in the iterative process.

The drag force between land and atmosphere is accounted by $r_{a}$, and this parameter requires the surface roughness conditions $\left(z_{0 h}\right)$ and friction velocities $\left(u_{*}\right)$ to be specified:

$$
r_{a}=\frac{\ln \left[\frac{(z-d)}{z_{0 h}}\right]-\Psi_{h}[(z-d) / L]}{k u_{*}}
$$

where $z_{0 h}(\mathrm{~m})$ is the roughness length governing transfer of heat and vapor away from the land surface into the atmosphere, $k$ is the von Karman's constant $(0.41), z(\mathrm{~m})$ is a reference height, $d(\mathrm{~m})$ is the displacement height taken as $4.67 z_{0 m}, \Psi_{h}$ is the stability correction due to buoyancy, and $L(\mathrm{~m})$ is the Obukhov length.

The atmospheric surface-layer similarity theory was applied, using universal functions suggested by Businger et al. (1971) for solving the integrated stability functions of temperature $\left(\Psi_{h}\right)$ and momentum $\left(\Psi_{m}\right)$.

The following expressions are used for unstable situations:

$$
\begin{gathered}
\Psi_{h}=2 \ln \left(\frac{1+x^{2}}{2}\right) \quad x=\left(1-16 \frac{z-d}{L}\right)^{\frac{1}{4}} \\
\Psi_{m}=2 \ln \left(\frac{1+x}{2}\right)+\ln \left(\frac{1+x^{2}}{2}\right)-2 \arctan (x)+\frac{\pi}{2}
\end{gathered}
$$

For stable situations, the following is applied:

$$
\Psi_{h}=\Psi_{m}=-5 \frac{z-d}{L}
$$

where $L$ can be calculated as

$$
L=-\frac{\rho_{a} c_{p} \mathcal{u}_{*}^{3} T_{a}}{k g H}
$$

where $g$ is the gravitational constant $\left(9.81 \mathrm{~m} \mathrm{~s}^{-2}\right)$ and $u_{*}$ expressed in $\mathrm{m} \mathrm{s}^{-1}$ is given by

$$
u_{*}=\frac{u k}{\ln \left[\frac{z-d}{z_{0 m}}\right]-\Psi_{m}}
$$


where $u$ is the wind speed at the blending height $\left(\mathrm{m} \mathrm{s}^{-1}\right)$ and $\Psi_{m}$ is the stability correction for momentum transport at the blending height.

After applying the SEBAL calibrated equations in 10 Landsat images acquired in the Brazilian semiarid conditions spanning the years from 2001 to 2007, the results from Teixeira et al. (2009a) for the energy balance components showed excellent agreements on $R_{n}$ and $\lambda E$. The coefficient of determination $\left(R^{2}\right)$ for $R_{n}$ was 0.94 , with a root-mean-square error (RMSE) of $17.5 \mathrm{~W} \mathrm{~m}^{-2}$. For $\lambda E, R^{2}$ was 0.93 , with a RMSE of $33.8 \mathrm{~W} \mathrm{~m}^{-2}$. Good agreements were achieved for $H$ and $G$. For $H, R^{2}$ was 0.83 . Part of the deviations could be attributed to the estimations of $z_{0 m}$. The RMSE for $H$ was $41.8 \mathrm{~W} \mathrm{~m}^{-2}$. For $G$ the local calibration yielded an $R^{2}$ of 0.81 , with the RMSE of $13.3 \mathrm{~W} \mathrm{~m}^{-2}$.

After calculating instantaneous values for $\lambda E$, the satellite overpass time value of the evaporative fraction $\left[\mathrm{EF}=\lambda E /\left(R_{n}-G\right)\right]$ is multiplied by the daily values net radiation $\left(R_{n_{24}}\right)$ to acquire the latent heat flux for $24 \mathrm{~h}\left(\lambda E_{24}\right)$ :

$$
\lambda E_{24}=\mathrm{EF}_{\text {inst }} R_{n_{24}}
$$

where $\mathrm{EF}_{\text {inst }}$ is the ratio of $\lambda E$ to the available energy at the satellite overpass time.

On the basis of field data (Teixeira 2008), Teixeira et al. (2009a) reported the need of adding a factor of 1.18 to extrapolate the instantaneous to daily values of EF, under the Brazilian semiarid region.

The daily values of $R_{n}$ can be described by the 24-h values of net shortwave radiation, with a correction term for net longwave radiation for the same timescale throughout the Slob equation:

$$
R_{n}=\left(1-\alpha_{0}\right) \mathrm{RS} \downarrow-a_{1} \tau_{\mathrm{s}}
$$

where $a_{1}$ is the regression coefficient of the relationship between net longwave radiation $\left(R_{n 1}\right)$ and atmospheric shortwave transmissivity $\left(\tau_{\mathrm{s}}\right)$ on a daily scale (Bruin de and Stricker 2000; Teixeira et al. 2008). The term $\tau_{\mathrm{s}}$ can be calculated by the ratio of RS $\downarrow$ measured by radiometers and the incident solar radiation at the top of the atmosphere $\left(R_{a}\right)$.

After multiplying $\mathrm{EF}_{\text {inst }}$ by 1.18 to obtain the daily values, Teixeira et al. (2009a) reported that the relation between the satellite and field measurements of daily ET presented both better $R^{2}$ of 092 and a RMSE of $0.38 \mathrm{~mm}^{\text {day }}{ }^{-1}$ comparing field data and satellite measurements in irrigated crops and natural vegetation from 2001 to 2007 in the Brazilian semiarid region.

SEBAL has been validated in grapes, peaches, and almonds from Spain, Turkey, and California. These validations revealed that accumulated values of ET predicted by the model are within several percent from the measured values (Bastiaanssen et al. 2008).

Considering that the field measurements have their own sources of errors, the SEBAL accuracy in the Brazilian semiarid region after field calibrations is satisfactory. However, the difficulties of applying the model for different moisture conditions along the year and the lack of applicability, as discussed in the introduction section, make its implementation a difficult task in some situations.

\subsubsection{Description and Validation of the SAFER Model}

In the present study SAFER algorithm (Teixeira et al. 2012a) was applied and validated using both MODIS and Landsat images. 
MODIS is an instrument onboard Terra platform with 36 spectral bands between 0.405 and $14.385 \mu \mathrm{m}$, acquiring data at three spatial resolutions (250, 500, and $1000 \mathrm{~m})$. The land product used in the present work, included in this chapter, was Level-1B (L1B) dataset, which contains radiances for these bands. Only four (two reflectance and two thermal bands) were used, being the reflective solar bands (bands 1 and 2, red and near infrared) with a spatial resolution of $250 \mathrm{~m}$ and the thermal emissive bands (bands 31 and 32) with a spatial resolution of $1000 \mathrm{~m}$.

The digital signals are written as scale integer (SI) representations, from which radiance for each band of the sensor $L_{b}\left(\mathrm{~W} \mathrm{~m}^{-2} \mathrm{sr}^{-1} \mu \mathrm{m}^{-1}\right)$ can be calculated by using scale and offset terms:

$$
\begin{gathered}
L_{b}=R_{\text {scale }}\left(\mathrm{SI}-R_{\text {offset }}\right) \\
R_{\text {scale }}=\frac{L_{\max }-L_{\min }}{32,767} \\
R_{\text {offset }}=-\frac{32,767 L_{\min }}{L_{\max }-L_{\min }}
\end{gathered}
$$

where SI is dimensionless, $R_{\text {scale }}$ is the radiance rescaling gain factor in $\mathrm{W} \mathrm{m} \mathrm{m}^{-2} \mathrm{sr}^{-1} \mu \mathrm{m}^{-1}, R_{\text {offset }}$ is a dimensionless radiance rescaling offset factor, $L_{\min }$ is the spectral radiance scaled to 0 in $\mathrm{W} \mathrm{m} \mathrm{m}^{-2} \mathrm{sr}^{-1} \mu \mathrm{m}^{-1}$, and $L_{\max }$ is the observed spectral radiance scaled to $32,767 \mathrm{in} \mathrm{W} \mathrm{m}^{-2} \mathrm{sr}^{-1} \mu \mathrm{m}^{-1}$.

Considering the MODIS red and infrared bands, $\alpha_{p_{b}}$ was calculated with Equation 6.4 by using, respectively, the bands 1 and 2. For $\alpha_{0}$ calculations the reflectance values for these bands were used, according to the following regression equation (Valiente et al. 1995):

$$
\alpha_{0}=a+b \alpha_{p 1}+c \alpha_{p 2}
$$

where $\alpha_{p 1}$ and $\alpha_{p 2}$ are the planetary albedo for bands 1 and 2 from MODIS satellite measurements, and $a, b$, and $c$ are the regression coefficients obtained comparing these measurements with field data for the years of 2002 and 2004 (Teixeira et al. 2008), thus already including the atmospheric effects through the radiation path. The values found for the Brazilian semiarid conditions were $0.08,0.41$, and 0.14 , respectively.

For the surface temperature $\left(T_{0}\right)$, the MODIS bands 31 and 32 were used with Equation 6.8 considering $L_{b}$ from these bands for conversion into $T_{\text {sat }}$. In this case, $k_{1}$ and $k_{2}$ were calculated with the following equations:

$$
\begin{gathered}
k_{1}=2 h c^{2} \lambda^{-5} 10^{-6} \\
k_{2}=\frac{h c}{s \lambda}
\end{gathered}
$$

where $h$ is the Planck constant $\left(6.62606896 \times 10^{-34} \mathrm{~J} \mathrm{~s}^{-1}\right), c$ is the speed of light $\left(2.99792458 \times 10^{8} \mathrm{~m} \mathrm{~s}^{-1}\right), s$ is the Boltzmann constant $\left(1.3806504 \times 10^{-23} \mathrm{~J} \mathrm{~K}^{-1}\right)$, and $\lambda$ is the center wavelength in meter.

An initial implementation of the split window technique (Coll and Caselles 1997), having the aerodynamic $T_{0}$ data from the same energy balance experiments as for $\alpha_{0}$ (Teixeira et al. 2008), showed that a simpler regression equation could be applied for deriving the $T_{0}$ 
with reasonable accuracy in relation to field experimental data in the Brazilian semiarid conditions:

$$
T_{0}=a T_{31}+b T_{32}
$$

where $T_{31}$ and $T_{32}$ are the brightness temperature from bands 31 and 32, and the regression coefficients $a$ and $b$ were equally 0.50 for the Brazilian semiarid conditions, also including the atmospheric effects through the radiation path.

The SAFER model was also applied to Landsat images, as in the case of the SEBAL algorithm, using bands 1 to 5 and 7 for $\alpha_{0}$ calculation and band 6 for acquiring $T_{0}$. Regression equations were again used with $\alpha_{0}$ and $T_{0}$ obtained in the field and satellite measurements (Teixeira et al. 2009a; Teixeira 2010).

The images of NDVI, $\alpha_{0}$, and $T_{0}$ are the only input parameters to model the ET/ET instantaneous values. This ratio was then multiplied by the daily grids of $\mathrm{ET}_{0}$ for estimating the ET large-scale values for $24 \mathrm{~h}$.

Both the surface resistance $\left(r_{\mathrm{s}}\right)$ and ET/ET 0 are related to the soil moisture conditions and so are the remote sensing parameters. On the basis of this principle, a second model was applied to calculate $r_{s}$ aiming a simplified vegetation classification. Studies examining relationships between vegetation indices with soil moisture and ET rates have been previously done in the semiarid region of Brazil (Teixeira et al. 2008; Teixeira et al. 2009a,b).

In our study, the following equation was used to acquire ET (Teixeira 2012a):

$$
\frac{\mathrm{ET}}{\mathrm{ET}_{0}}=\exp \left[a+b\left(\frac{T_{0}}{\alpha_{0} \mathrm{NDVI}}\right)\right]
$$

where $a$ and $b$ are the regression coefficients, being 1.9 and $-0.008^{\circ} \mathrm{C}^{-1}$, respectively, for the Brazilian semiarid conditions.

The Landsat satellite overpass time ET/ET 0 values and those for $24 \mathrm{~h}$ in irrigated mango orchards and Caatinga have been compared in a previous study, being the slope of the ET/ $\mathrm{ET}_{0}$ regression between satellite and field values close to 1.0 (Teixeira 2010). These results support the assumption that instantaneous and daily values for this ratio can be considered similar under cloud-free conditions (Allen et al. 2007).

To separate the energy balance components, including ET, from irrigated crops and natural vegetation, the following equation was applied with threshold values for $r_{s}$ (Teixeira 2012b):

$$
r_{s}=\exp \left[a\left(\frac{T_{0}}{\alpha_{0}}\right)(1-\mathrm{NDVI})+b\right]
$$

where $r_{s}$ is given in $\mathrm{s} \mathrm{m}^{-1}$, and $a$ and $b$, being $-0.04 \mathrm{~s} \mathrm{~m}^{-1}{ }^{\circ} \mathrm{C}^{-1}$ and 2.72 , respectively, are the regression coefficients found for the semiarid conditions of Brazil.

To retrieve the daily values $R_{n}$, Equation 6.26 was also used. On average, the $a_{1}$ coefficient for the agroecosystems under the Brazilian semiarid conditions was found to be 143. Because of the $T_{a}$ dependency on longwave radiation, it was investigated whether the variations of $a_{1}$ could be explained by those in the $24 \mathrm{~h} T_{a}$ values (Teixeira et al. 2008):

$$
a_{1}=b T_{a}-c
$$


where $T_{a}$ is in ${ }^{\circ} \mathrm{C}$, and $b$ and $c$ were $7^{\circ} \mathrm{C}$ and 39.9, respectively, for the Brazilian semiarid conditions.

Transforming ET into energy units through the relation of $1 \mathrm{MJ} \mathrm{m}^{-2}$ day $^{-1}=0.408 \mathrm{~mm}$ day $^{-1}$ (Allen et al. 1998), $\lambda E$ was quantified on a 24-h basis, and $H$ was acquired as a residual in Equation 6.1, neglecting $G$ for this timescale. Teixeira et al. (2008) has demonstrated that 24-h values for this last energy balance component is close to zero for irrigated crops and natural vegetation in the Brazilian semiarid region.

Equation 6.12 was also used for RL $\downarrow$ but with daily values of 0.94 and 0.11 for the $a$ and $b$ regression coefficients in Equation 6.13, respectively (Teixeira 2008). Having the grids of RS $\downarrow$ from the agrometeorological stations, the values for RL $\uparrow$ on a large scale could be estimated as a residual in Equation 6.2.

To test the validity of Equation 6.34, Teixeira (2010) used field and remote sensing parameterizations, with 10 different Landsat images in the Brazilian semiarid region. The results showed good agreement, with $R^{2}=0.89$ and RMSE of $0.34 \mathrm{~mm}^{-1}{ }^{-1}$, fitting very well the line 1:1 when comparing the ET values in irrigated crops and natural vegetation.

\subsection{Comparison between SEBAL and SAFER Methods}

The challenges to make the remote sensing models applicable should be the implementation of agrometeorological stations, coupling weather data with satellite measurements and testing the algorithms over a diverse range of ecosystems. Although easier than SEBAL, before analyzing SAFER applications on a large scale in the Brazilian semiarid region, comparisons between the ET results from both models against water application by the FAO 56 approach (Allen et al. 1998) were first realized.

Different crops and soil cover conditions were considered in the northwestern side of São Paulo State, southeast Brazil. The studied commercial Bonança farm in São Paulo has central coordinates of $20^{\circ} 41^{\prime} 40^{\prime \prime} \mathrm{S}$ and $50^{\circ} 59^{\prime} 02^{\prime \prime} \mathrm{W}$. One Landsat image acquired in July 12, 2010 (80 days after the last rain), was used together with weather data from an agrometeorological station close to the farm. The comparisons were done taking into account 20 center pivots covering a total irrigated area of 2110 ha with corn, bean, and sugar cane.

For using the SAFER model in São Paulo, the $a$ coefficient of Equation 6.34 was first set to 1.0 considering the similarity between $K_{c}$ values generally adopted by the farmer from $\mathrm{FAO}$ guidelines and $\mathrm{ET} / \mathrm{ET}_{0}$ results from the model in the wettest portions of the pivot irrigation areas for each specific crop.

The ET images obtained from the application of the two remote sensing algorithms are shown in Figure 6.2.

The center pivots of numbers 1-2 and 6-16 are corn, with the number 9 at the resting stage; 3 and 5 are bean; and 17-20 are sugar cane. The crops are at different days after planting (DAP) with pivot areas ranging from 70 to 160 ha.

One can clearly see the lower degree of uniformity of the ET values from SEBAL (Figure 6.2a) than for SAFER (Figure 6.2b) inside well-irrigated pivot areas. The average standard deviation (SD) for first method was $0.22 \mathrm{~mm}_{\text {day }}{ }^{-1}$, while for the second one, the mean SD was $0.16 \mathrm{~mm}^{-1} \mathrm{may}^{-1}$, indicating $38 \%$ more variation with SEBAL method than when applying the SAFER algorithm. As a first guess, the SEBAL results are less realistic, considering that inside the fully irrigated pivot areas, the water is, in general, uniformly applied. 

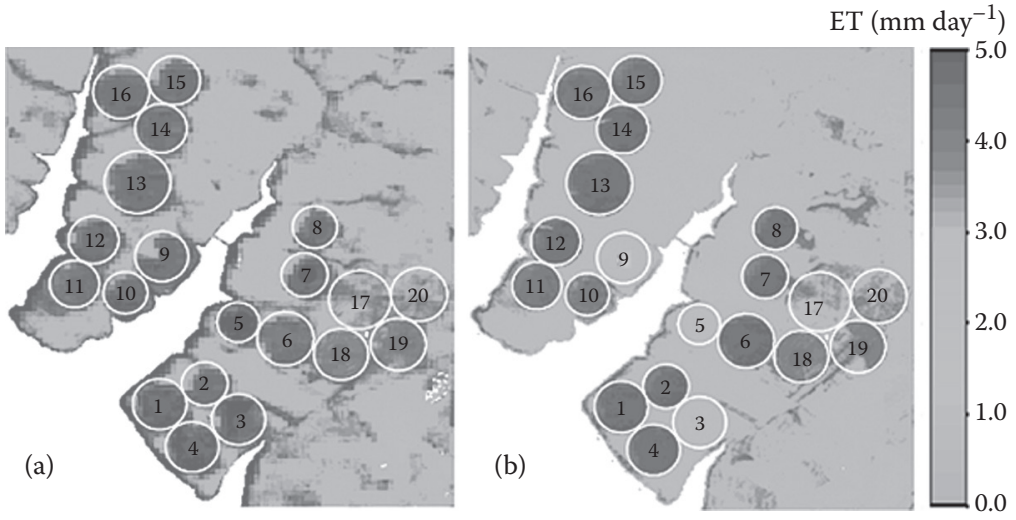

FIGURE 6.2

(See color insert.) Daily evapotranspiration (ET) from applications of (a) SEBAL and (b) SAFER models in a Landsat image acquired in July 12, 2010, for pivot center irrigated areas inside the Bonança farm, northwestern São Paulo, Brazilian southeast.

In fact, the generalized low SD values, around $0.20 \mathrm{~mm}^{-1 a y}{ }^{-1}$ for both algorithms, indicate reasonable uniformity of water application in the areas covered by the pivots, with the highest one for pivot 9. This last lack of uniformity is noted mainly for the SEBAL method, when the SD was $0.70 \mathrm{~mm}^{\text {day }}{ }^{-1}$, while with SAFER application it was $0.30 \mathrm{~mm}$ day $^{-1}$. The reason for this as well as the difference between models is that the resting corn crop was with a very small pivot area being irrigated and low soil cover.

Comparing the ET rates from SEBAL and SAFER methods with the farm water management based on the FAO $K_{c}$ methodology for all irrigation pivots, these rates were $45 \%$ and $29 \%$ higher, respectively. The RMSE was calculated taking the water applied as a reference according to DAP for bean (pivots 3 and 5 at 5 and 13 DAP, respectively) and corn crops (pivots 1-2 and 6-16, after 75 DAP). The results are shown in Figure 6.3.

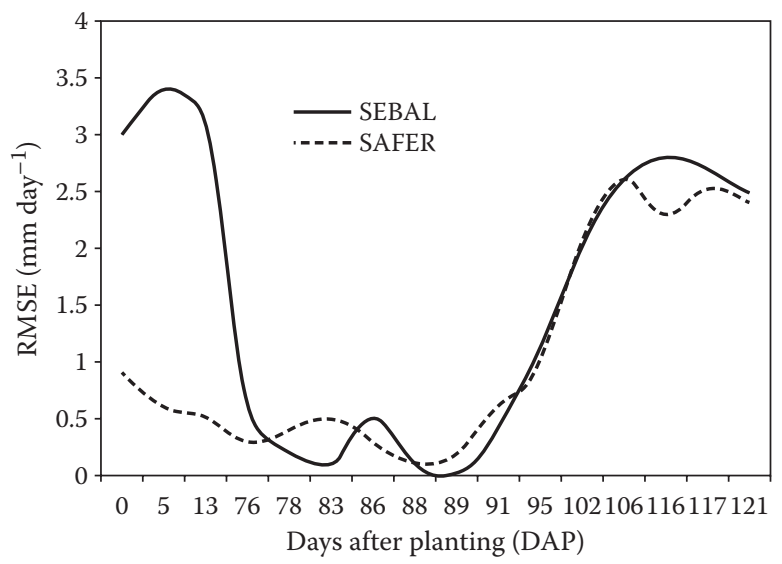

FIGURE 6.3

Relations between the root-mean-square errors (RMSE) from SEBAL and SAFER methods when comparing with water management based on FAO methodology taking as reference and according to the day after planting (DAP) for corn and bean crops. 
In general, the ET results from both SAFER and SEBAL algorithms agreed well with water application from FAO methodology during the days with DAP from 75 to 95, with RMSE values around $0.4 \mathrm{~mm}^{\text {day }}{ }^{-1}$. However, after this period, water application differed very much from ET results from both remote sensing methods, which presented good agreements between them, indicating a possibility of the use of low $K_{c}$ values by the farmer after DAP $=95$. The RMSE values for SEBAL algorithm at the initial stages are much larger than those for SAFER method.

Although sugar cane crops were not irrigated at the Landsat image acquirement day, the high ET rates in the pivots 18 and 19 (Figure 6.2) from both methods indicated sufficient soil moisture at the root zones. As the sugar cane crops were with high leaf areas $(\mathrm{DAP}=120)$, and considering the similarity of the RMSE values at high DAP from Figure 6.3, the good agreements between SEBAL and SAFER in situations of large soil cover are reinforced.

Despite the disagreements between methods at low soil cover, satellite measurements can identify the crop stages, and the results indicated that in some situations these stages should be taken into account more accurately and objectively by the farmer, as for example, by applying relations between $K_{c}$ and the accumulated degree days. According to Teixeira (2009), the advantage of using this relationship is the $K_{c}$ values transfer to different thermal conditions during the crop stages.

One of the reasons for the differences between SEBAL and SAFER results in relation to water applied based on the FAO $K_{c}$ methodology could be that the first algorithm gives much weight for the surface temperature that is calculated from thermal bands that have lower spatial resolution than the visible and near infrared ones and then $H$ is obtained iteratively. At the crop initial stages the thermal conditions are more differentiated and the accuracy for obtaining $G$ is also questionable for retrieving $\lambda E$ as residual in Equation 6.1 at the satellite overpass time. With application of the SAFER method, $\lambda E$ is acquired first than $H$ and the ratio ET/ET ${ }_{0}$ is related to $\alpha_{0}, \mathrm{NDVI}$, and $\mathrm{ET}_{0}$, which, in turn, combine the soil-water-vegetation-atmosphere relations.

After having more confidence in SAFER algorithm, and considering also its applicability together with agrometeorological stations, it was applied in MODIS and Landsat satellite images to acquire ET on a municipality scale in the Brazilian semiarid region. Additional data of RS $\downarrow, T_{a}$ and $\mathrm{ET}_{0}$ from automatic and conventional agrometeorological stations allowed retrieving the trend of the energy balance components at the irrigation scheme scale along the years.

\subsection{Retrieving the Energy Balance Components at Different Spatial and Temporal Scales Using SAFER Modeling Scheme}

The monthly ET values were analyzed for Petrolina (PE) municipality with MODIS images, while for Juazeiro (BA) municipality, this was done with Landsat images considering daily and annual timescales. For the Nilo Coelho irrigation scheme, Landsat images during the driest periods along the years were used for quantifying the land use change effects on the energy balance components as consequences of the replacement of natural vegetation by irrigated crops in the Brazilian semiarid conditions. The results and analyses are described throughout the following sections. 


\subsubsection{Evapotranspiration at the Municipality Scale}

After calculating ET by applying the SAFER algorithm for the entire area showed in the right side of Figure 6.1 from MODIS and Landsat images, Petrolina (PE) and Juazeiro (BA) municipalities were extracted for water flux analyses at different spatial and temporal scales.

\subsubsection{Monthly Evapotranspiration from the Petrolina Municipality}

Fifteen ET/ET 0 MODIS images, with 6 days for 2010 and 9 for 2011, were used together with grids of the $\mathrm{ET}_{0}$ monthly values during the year of 2011, representing different thermohydrological conditions along a year in the Brazilian semiarid region. The calculations involved the entire area involved by the agrometeorological stations showed in the right side of Figure 6.1. Petrolina municipality, Pernambuco (PE) state, northeast Brazil, was extracted for the monthly water fluxes analyses. Figure 6.4 presents the spatial distribution of the ET monthly values for 2011 after interpolation and averaging processes along the year.

Considering the Petrolina municipality as a whole, the spatial and temporal variation of ET along the year is evident, mainly when comparing the wettest period from February to April with the driest one, between July and September. During the rainy period the maximum ET values are verified in April, with an average of $61 \mathrm{~mm} \mathrm{month}{ }^{-1}$. In November, there is another pick with a mean value of $58 \mathrm{~mm} \mathrm{month}^{-1}$. Intermediate water fluxes in natural vegetation occur just after the rainy season, from May to June, because the antecedent precipitation from January to April still keeps the Caatinga brushes wet and green.

As a consequence of the highest portions of the available energy used as $H$ in Caatinga, during the driest period of the year from July to October, this natural vegetation presents the lowest ET values, while the irrigated fields show the highest ones. Stomata close in Caatinga species during the driest land conditions, limiting transpiration and photosynthesis, and, in general, irrigation intervals in agricultural crops are short (daily irrigation), with uniform water supplies, reducing the heat losses to the atmosphere.

ET (mm month $\left.{ }^{-1}\right)$

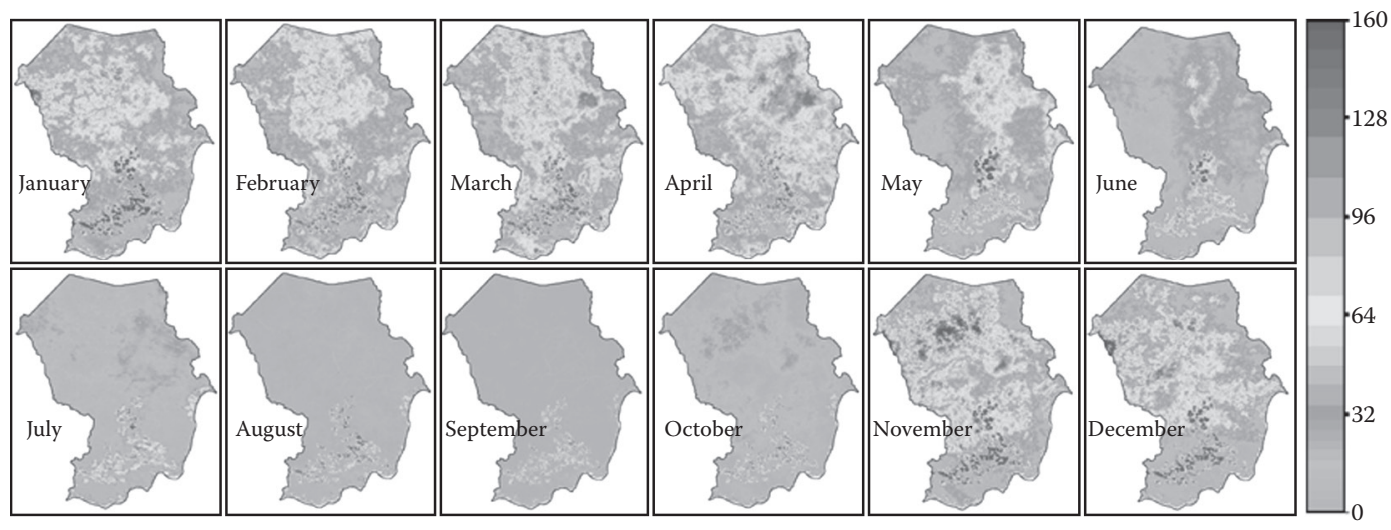

FIGURE 6.4

(See color insert.) Spatial distribution of the monthly values of evapotranspiration from MODIS images through SAFER model for the year 2011 in the Petrolina municipality, Pernambuco State, northeast Brazil. 
According to Figure 6.4, moisture condition effects on the magnitude of the ET rates are strong. Pixels with values lower than $1.0 \mathrm{~mm} \mathrm{month}^{-1}$ occur during the dry season representing very dry natural vegetation. The highest SD of $35 \mathrm{~mm}$ month $^{-1}$ happened in November, as a consequence of the coupled effect of the start of the rains and the heterogeneity caused by differences of the crop stages, while the driest month of September presents the lowest SD of $17 \mathrm{~mm}$ month $^{-1}$.

Considering the whole year, the average annual ET rate for the mixture of agroecosystems was $438 \pm 235 \mathrm{~mm}$ year $^{-1}$. Previous remote sensing studies in the semiarid conditions of the Brazilian northeast reported the highest annual ET values for table grapes and mango orchards with those for natural vegetation close to the amounts of annual rainfall (Teixeira et al. 2009b).

\subsubsection{Daily and Annual ET from the Juazeiro Municipality}

Still considering the municipality scale, three Landsat images for specific days on January 20, 2007, June 10, 2011, and November 17, 2009, were used to compute the daily ET rates also for the entire area involved by the agrometeorological stations showed on the right side of Figure 6.1. These dates represent different thermohydrological conditions along a year in the Brazilian semiarid region. The averaged $\mathrm{ET} / \mathrm{ET}_{0}$ image was multiplied by the grid of $\mathrm{ET}_{0}$ for 2010 and the Juazeiro (BA) municipality extracted for quantification and analyses of the daily and annual ET rates together with the annual frequency histogram (Figure 6.5).

(a)

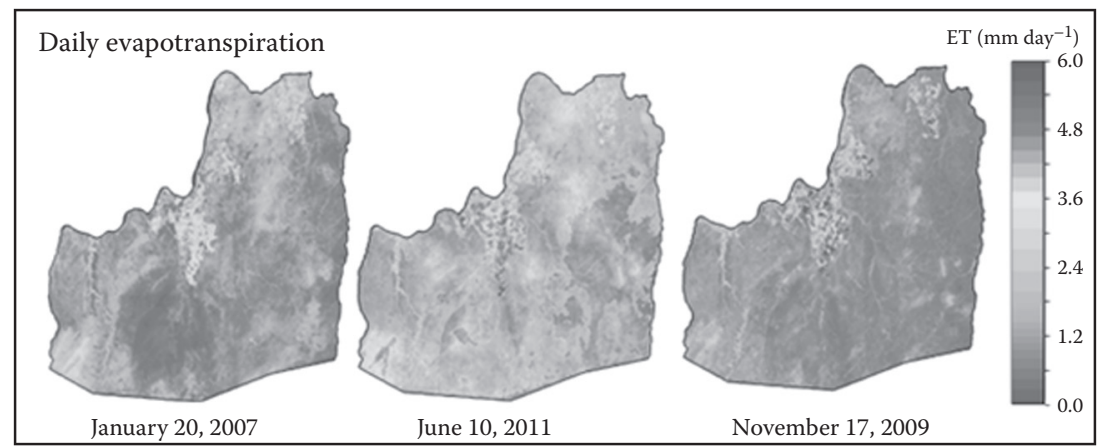

(b)

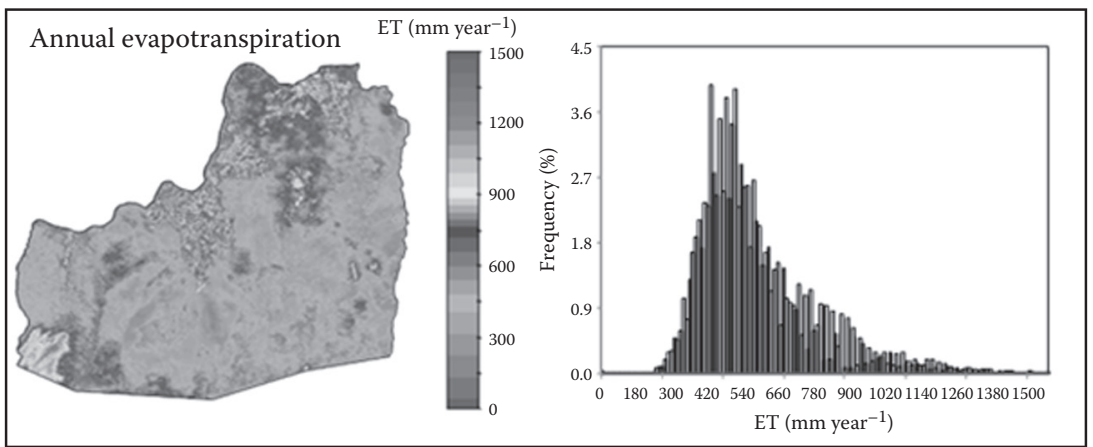

FIGURE 6.5

(See color insert.) Spatial distribution of evapotranspiration from Landsat images throughout the SAFER model in the Juazeiro municipality, Bahia (BA) State, northeast Brazil. (a) For specific days representative of different thermohydrological conditions along the year and (b) for the year 2010 together with annual ET frequency histogram. 
According to Figure 6.5a, one can see the concentration of irrigated crops by the highest daily ET values in the superior portion of the Juazeiro municipality, closer to the São Francisco River.

At the start of the rainy period (represented by the image of January 20, 2007), the farmers, in general, do not irrigate, and some grape plots are under the resting stage, promoting ET daily values lower than $3.5 \mathrm{~mm}^{-1 a y}{ }^{-1}$ in irrigated areas. Considering natural vegetation, some Caatinga species are benefitted by the first rains and thus presenting high rates of biomass production. Under these conditions, considering the entire municipality, the average ET daily rate was $1.3 \mathrm{~mm}$ day $^{-1}$.

The daily ET rates rapidly increase after the rainy period (represented by the image of June 10, 2011) in both irrigated plots and natural vegetation areas. In irrigated areas, this is because the farmers reactivate the irrigation systems under continuous increases in the thermal conditions and there are much new vineyard growing seasons. Considering natural vegetation, the antecedent rains keep enough soil moisture at the root zone of the Caatinga species, leaving this ecosystem still actively consuming water. Under these circumstances the municipality ET daily values are around $1.9 \mathrm{~mm}^{\text {day }}{ }^{-1}$.

During the driest period of the year (represented by the image of November 17, 2009), Caatinga converts large portion of the available energy into $H$, presenting the lowest ET daily rates. The commercial crops are with the highest values of the year, above $4.5 \mathrm{~mm}$ day $^{-1}$ in well-irrigated plots, mainly from mango orchards and vineyards. In general, the irrigation intervals for these crops are short in absence of rains, and the water supply is uniform, lowering $H$ while increasing $\lambda E$. At the municipality scale, the daily ET rates are the lowest of the year, around $1.2 \mathrm{~mm}$ day $^{-1}$, owing to the largest area covered by dry natural vegetation.

From Figure 6.5b, the annual ET values representing Caatinga species are concentrated between 300 and $600 \mathrm{~mm}_{\text {year }}^{-1}$, while for irrigated crops they are in the range from 900 to $1500 \mathrm{~mm}_{\text {year }}{ }^{-1}$. Pixels with the highest frequency present annual ET values around $500 \mathrm{~mm}$ year $^{-1}$; this low rate is a consequence of the predominance of the natural vegetation away from the bank of the São Francisco River.

Considering the annual average ET value for the whole Juazeiro municipal district, it was $40 \mathrm{~mm}$ year ${ }^{-1}$; however, with a large standard deviation of $200 \mathrm{~mm}^{\text {year }}{ }^{-1}$, evidencing the strong hydrological heterogeneity, as a consequence of the mixed natural and irrigated agroecosystems.

\subsubsection{Energy Balance at the Irrigation Scheme Scale}

For the irrigation perimeter scale, 10 Landsat images for the driest period of the year, from 1992 to 2011, were used to quantify the evolution of the daily available energy partition $\left(R_{n}\right)$ into $\lambda E$ and $H$ in the Nilo Coelho irrigation scheme. A conventional station, named Bebedouro, located at the Petrolina (PE) municipality (see Figure 6.1), together with an automatic one at the same place, was used in addition to apply regression equations for estimating the interpolated daily weather parameters before 2003.

After interpolations of RS $\downarrow, T_{a}$ and $\mathrm{ET}_{0}$ together with the remote sensing parameters $\alpha_{0}$, $T_{0}$, and NDVI for all area showed in the right side of Figure 6.1, the irrigation perimeter was extracted for analyses of the energy balance components to see their trends along the years in the measure that the Caatinga species were replaced by irrigated crops.

The spatial and temporal variations for the daily values of the energy balance components resulted from Landsat images processing for each day/year from 1992 to 2011 in the Nilo Coelho irrigation scheme are presented in Figure 6.6. 

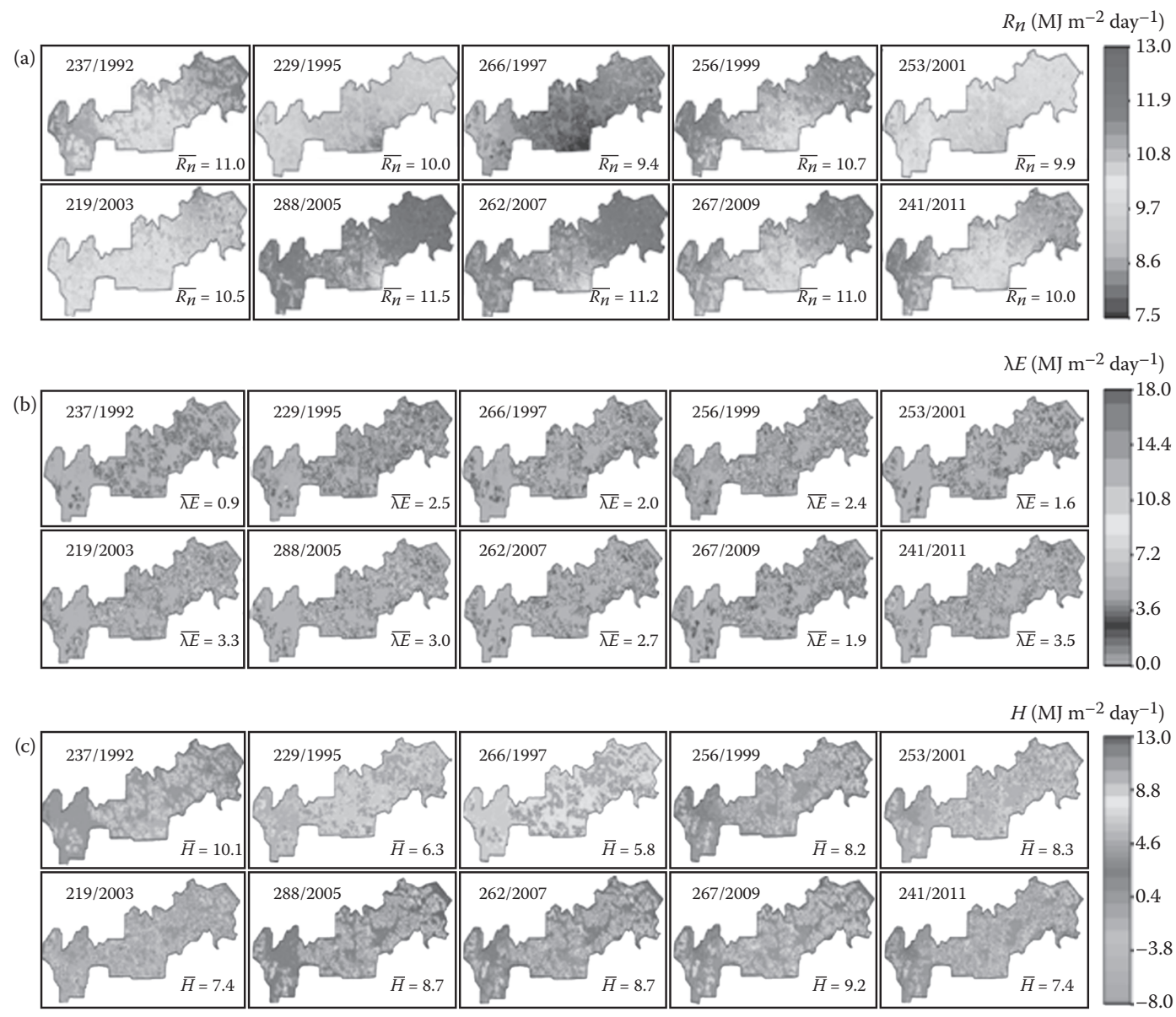

FIGURE 6.6

(See color insert.) Spatial and temporal variation of the daily energy balance components from Landsat images processing by the SAFER model and Slob equation, for the driest periods of the year, from 1992 to 2001, in the Nilo Coelho irrigation scheme, Brazil: (a) net radiation $\left(R_{n}\right)$, (b) latent heat flux $(\lambda E)$, and (c) sensible heat flux $(H)$. The bars mean average pixel values.

Figure 6.6a shows the spatial variation of the daily available energy $\left(R_{n}\right)$, neglecting $G$ for this timescale. The fraction of RS $\downarrow$ transformed into $R_{n}$ ranged from $42 \%$ to $50 \%$, averaging $46 \%$, confirming the assumption of this ratio being around $50 \%$ throughout field measurements in the Brazilian semiarid region (Teixeira et al. 2008). These agreements give more confidence for modeling the daily energy balance components by using Landsat satellite images and agrometeorological stations on a large scale.

In general, there is no clear distinction among the $R_{n}$ pixel values from irrigated plots and natural vegetation areas along the years, as, for example, comparing the similar day of the year represented by the images for 1992 and 2011, with the largest difference in terms of land use change. Also, there are no large spatial distinctions in the SD values, which ranged from 0.40 to $0.55 \mathrm{MJ} \mathrm{m}^{-2}$ day $^{-1}$. The strongest $R_{n}$ dependence is on RS $\downarrow$, with the largest $R_{n}$ mean pixel value in 2005 (Figure 6.6a) corresponding to the highest level of RS $\downarrow$ $\left(25.4 \mathrm{MJ} \mathrm{m}^{-2} \mathrm{~d}^{-1}\right)$, among the 10 days analyzed. 
Clearly, one can distinguish irrigated areas from Caatinga species by the largest $\lambda E$ pixel values and the lowest ones for $H$ under irrigation conditions (Figure 6.6b and c). $H$ is even sometimes negative in the cropped areas, meaning heat horizontal advection from the warmer natural vegetation at the vicinities of irrigated plots. This happens mainly in crops with microsprinkler irrigation systems rather than those in drip irrigated ones (Teixeira 2009).

In relation to the daily $\lambda E$ pixel values (Figure 6.6b), their increments along the years are evident. Considering the entire irrigation perimeter, the average $\lambda E$ values increased $390 \%$ from 1992 to 2011. This means that the replacement of Caatinga species by irrigated crops raised almost four times the water vapor transferred to the lower atmosphere considering the period outside the rainy season. Declines in $H$ along the years are also clear, with the average value in 1992 representing 136\% of that for 2011 (Figure 6.6c). The extra water use by irrigated crops increases evapotranspiration and reduces air temperature close to the vegetated surfaces. This reduction together with increases in $r_{a}$ contributes to declines in the $H$ pixel values.

Considering the entire irrigation perimeter area, from 1992 to 1997, when the irrigated area was starting to increase, strong heat advection from the dry natural vegetation to irrigated areas is observed by the negative $H$ values, making $\lambda E$ larger than $R_{n}$ in very well irrigated parcels. The spatial variations in both fluxes are large, with an SD value around $3.5 \mathrm{MJ} \mathrm{m}^{-2}$ day $^{-1}$. Only at the start of the irrigation project in 1992 can one see a small spatial flux variation with an SD lower than $2.0 \mathrm{MJ} \mathrm{m}^{-2}$ day $^{-1}$ for both $\lambda E$ and $H$ (Figure 6.6b and c).

The trends of the average fractions of $\lambda E$ and $H$ to $R_{n}$ along the years from 1992 to 2011 were also quantified for the images depicted in Figure $6.6 \mathrm{~b}$ and c. Threshold values of 800 and $10,000 \mathrm{~s} \mathrm{~m}^{-1}$ for $r_{s}$ and conditional functions were applied to the image of the day/year 267/2009 for a vegetation classification. Following Teixeira (2012b), areas with $r_{s}$ values lower than $800 \mathrm{~s} \mathrm{~m}^{-1}$ were considered irrigated crops; between this lower limit and $10,000 \mathrm{~s} \mathrm{~m}^{-1}$ they were assumed natural vegetation; and higher than this last value, they were considered features in the image that are not vegetation.

During these years the averaged fractions of $R_{n}$ used as $\lambda E$ for the entire area increased from $8 \%$ to $32 \%$, while in irrigated areas the corresponding fractions were from $50 \%$ to $80 \%$. Taking into account only irrigation conditions the mean $\lambda E$ raised from $5.6 \mathrm{MJ} \mathrm{m}^{-2}$ day $^{-1}$ in 1992 to $8.4 \mathrm{MJ} \mathrm{m}^{-2}$ day $^{-1}$ in 2011, equivalent to ET rates from 2.3 to $3.4 \mathrm{~mm} \mathrm{day}^{-1}$. On an opposite situation, $H / R_{n}$ values were $92 \%$ and $69 \%$ for the entire perimeter and $71 \%$ and $20 \%$ when taking into account only irrigated areas. In irrigation conditions, the $H$ mean values ranged from $7.7 \mathrm{MJ} \mathrm{m}^{-2}$ day $^{-1}$ in 1992 to $2.2 \mathrm{MJ} \mathrm{m}^{-2}$ day ${ }^{-1}$ in 2011.

Separating the natural vegetation from the entire irrigation perimeter area, it was observed that the energy partition is more steady, as in the absence of rains, the ET rates of the Caatinga species are very small, with $\lambda E / R_{n}$ and $H / R_{n}$ around 0.06 and 0.93 , respectively, during the driest conditions of the year. The main characteristic for the energy exchange from the natural vegetation in the Brazilian semiarid region is the conversion of large portions of the available energy into $H$ flux.

\subsection{Final Remarks}

Considering the two algorithms for acquiring evapotranspiration analyzed in this chapter, the advantage of SAFER in relation to SEBAL is the absence of the need of neither crop classification nor hydrological extreme conditions, without the background knowledge in 
radiation physics. For rainy conditions, the assumption of zero latent heat flux by SEBAL is not realistic because of the absence of dry pixels. An additional advantage of SAFER is the possibility of using daily weather data from either conventional and/or automatic agrometeorological stations, making possible a historical evaluation of the energy balance components.

When comparing the SAFER and SEBAL algorithms with the traditional FAO methodology for water requirement quantification, it was concluded that under low soil cover, the first model showed more consistence with crop stages than the second one. After having more confidence in SAFER algorithm, coupling remote sensing parameters from MODIS and Landsat satellite images with weather data, the energy balance assessments were possible in a mixture of agroecosystems at the municipality and irrigation scheme scales, in the Brazilian semiarid region.

The largest evapotranspiration rates in the semiarid region of Brazil were in November for irrigated crops and in April for natural vegetation. The acquirements of the energy balance components outside the rainy period in the Nilo Coelho irrigation scheme allowed a better understanding of the energy fluxes on an irrigated perimeter level. These acquirements are important for appraising the impact of land use changes on the regional scale energy and water fluxes.

It could be concluded that net radiation values are very strongly dependent on global solar radiation independent of the type of vegetation. The averaged fractions of net radiation used as latent heat flux for the entire Nilo Coelho perimeter increased from $8 \%$ to $32 \%$ from 1992 to 2011, while in irrigated areas these fractions were from 50\% to 80\%, revealing that in the measure in which the irrigated area increases much more, the available energy is used in the evapotranspiration processes.

To make the SAFER model applicable together with weather data over a more diverse range of ecosystems, there is the need of adjusting the coefficients of the equation relating the ratio $\mathrm{ET} / \mathrm{ET}_{0}$ with the retrieving remote sensing parameters. After this calibration and with additional estimations on net radiation in conjunction with a network of agrometeorological stations, the energy exchanges in different agroecosystems can be well quantified and monitored on a large scale.

\section{Acknowledgments}

The research herein was supported by FACEPE and CNPq for the financial support to the actual project on Water Productivity in the São Francisco River Basin, Brazil.

\section{References}

Allen, R. G., L. S. Pereira, D. Raes, and M. Smith. 1998. Crop Evapotranspiration: Guidelines for Computing Crop Water Requirements. Food and Agriculture Organization, Rome.

Allen, R. G., M. Tasumi, A. Morse, R. Trezza, J. Wright, W. Bastiaanssen, W. Kramber, I. Lorite, and C. Robison. 2007. Satellite-based energy balance for mapping evapotranspiration with internalized calibration (METRIC)—Applications. J. Irrig. Drain. Eng. ASCE 133: 395-406. 
Anderson, M. C., W. P. Kustas, J. G. Alfieri, F. Gao, C. Hain, J. H. Prueer, S. Evett, P. Colaizzi, T. Howell, and J. L. Chávez. 2012. Mapping daily evapotranspiration at Landsat spatial scales during BEAREX'08 field campaign. Adv. Water Res. 50: 162-177.

Bastiaanssen, W. G. M., R. A. L. Brito, M. G. Bos, R. A. Souza, E. B. Cavalcanti, and M. M. Bakker. 2001. Low cost satellite data for monthly irrigation performance monitoring: Benchmarks from Nilo Coelho, Brazil. Irrig. Drain. Syst. 15: 53-79.

Bastiaanssen, W. G. M., M. Menenti, R. A. Feddes, G. J. Roerink, and A. A. M. Holtslag. 1998. A remote sensing surface energy balance algorithm for land (SEBAL) 1. Formulation. J. Hydrol. 212-213: 198-212.

Bastiaanssen, W. G. M., H. Pelgrum, R. W. O. Soppe, R. G. Allen, B. P. Thoreson, and A. H. de C. Teixeira. 2008. Thermal infrared technology for local and regional scale irrigation analysis in horticultural systems. Acta Hort. 792: 33-46.

Bruin de, H. A. R., and J. N. M. Stricker. 2000. Evaporation of grass under nonrestricted soil moisture conditions. Hydrol. Sci. 45: 391-406.

Businger, J. A., J. C. Wyngaard, Y. Izumi, and E. F. Bradley. 1971. Flux-profile relationships in the atmospheric surface layer. J. of Atm. Sci. 28: 189-191.

Cleugh, H. A., R. Leuning, Q. Mu, and S. W. Running. 2007. Regional evaporation estimates from flux tower and MODIS satellite data. Remote. Sens. Environ. 106: 285-304.

Coll, C., and V. A. Caselles. 1997. Split-window algorithm for land surface temperature from advanced very high resolution radiometer data: validation and algorithm comparison. J. Geophys. Res. 102: 16,697-16,714.

Hernandez, F. B. T., A. H. de C. Teixeira, C. M. U. Neale, and S. Tahvaein (in press). Determining actual evapotranspiration and crop coefficient in large scale using weather station and remote sensing in the Northwest of the State of São Paulo, Brazil. Acta Hort.

Kalma, J. D., and D. L. B. Jupp. 1990. Estimating evaporation from pasture using infrared thermometry: Evaluation of a one-layer resistance model. Agric. For. Meteorol. 51: 223-246.

Kustas, W. P., M. C. Anderson, A. N. French, and D. Vickers. 2006. Using a remote sensing field experiment to investigate flux-footprint relations and flux sampling distributions for tower and aircraft-based observations. Adv. Water Resour. 29: 355-368.

Kustas, W. P., and J. M. Norman. 1999. Evaluation of soil and vegetation heat flux predictions using a simple two-source model with radiometric temperatures for partial canopy cover. Agric. For. Meteorol. 94: 13-29.

Liu, J., J. M. Chen, and J. Cihlar. 2003. Mapping evapotranspiration based on remote sensing: An application to Canada's landmass. Water Resour. Res. 39: 1189-1200.

Majumdar, T. J., R. Brattacharyya, and S. Chattejee. 2007. On the utilization of ENVISAT AATSR data for geological/hydrological applications. Acta Astron. 60: 899-905.

Menenti, M., and B. J. Choudhury. 1993. Parameterization of land surface evaporation by means of location dependent potential evaporation and surface temperature range. In Exchange Processes at the Land Surface for a Range of Space and Time Scales (H.-J. Bolle, R. A. Feddes, J. D. Kalma, Eds.), vol. 212. IAHS Press, Oxford, pp. 561-568.

Miralles, D. G., T. R. H. Holmes, R. A. M. De Jeu, J. H. Gash, A. G. C. A. Meesters, and A. J. Dolman. 2011. Global land-surface evaporation estimated from satellite-based observations. Hydrol. Earth Syst. Sci. 15: 453-469.

Norman, J. M., M. C. Anderson, W. P. Kustas, A. N. French, J. Mecikalski, R. Torn, G. R. Diak, T. J. Schmugge, and B. C. W. Tanner. 2003. Remote sensing of surface energy fluxes at 101-m pixel resolutions. Water Resour. Res. 39: 1221.

Norman, J. M., W. P. Kustas, J. H. Prueger, and G. R. Diak. 2000. Surface flux estimation using radiometric temperature: A dual-temperature-difference method to minimize measurement errors. Water Resour. Res. 36: 2263-2274.

Pôças, I., M. Cunha, L. S. Pereira, and R. G. Allen. 2013. Using remote sensing energy balance and evapotranspiration to characterize montane landscape vegetation with focus on grass and pasture lands, Int. J. Appl. Earth Obs. Geoinf. 21: 159-172. 
Roerink, G. J., Z. Su, and M. Menenti. 2000. S-SEBI: A simple remote sensing algorithm to estimate the surface energy balance. Phys. Chem. Earth 25: 147-157.

Schmugge, T., S. I. Hook, and C. Coll. 1998. Recovering surface temperature and emissivity from thermal infrared multispectral scanner data. Remote Sens. Environ. 65: 121-131.

Schneider, K., and W. Mauser. 1996. Processing and accuracy of Landsat Thematic Mapper data for lake surface temperature measurement. Int. J. Remote Sens. 17: 2027-2041.

Smith, R. G. C., H. D. Barrs, and W. S. Meyer. 1989. Evaporation from irrigated wheat estimated using radiative surface temperature: An operational approach. Agric. For. Meteorol. 48: 331-344.

$\mathrm{Su}, \mathrm{Z}$. 2002. The Surface Energy Balance System (SEBS) for estimation of turbulent heat fluxes. Hydrol. Earth Syst. Sci. 6: 85-99.

Su, H., M. F. McCabe, E. F. Wood, Z. Su, and J. H. Prueguer. 2005. Modeling evapotranspiration during SMACEX02: Comparing two approaches for local and regional scale prediction. J. Hydrometeorol. 6: 910-922.

Tang, Q., E. A. Rosemberg, and D. P. Letenmaier. 2009. Use of satellite data to assess the impacts of irrigation withdrawals on Upper Klamath Lake, Oregon. Hydrol. Earth Syst. Sci. 13: 617-627.

Tasumi, M., and R. G. Allen. 2007. Satellite-based ET mapping to assess variation in ET with timing of crop development. Agric. Water Manage. 88: 54-62.

Teixeira, A. H. de C. 2009. Water Productivity Assessments from Field to Large Scale: A Case Study in the Brazilian Semiarid Region; LAP Lambert Academic Publishing, Saabrücken, Germany.

Teixeira, A. H. de C. 2010. Determining regional actual evapotranspiration of irrigated and natural vegetation in the São Francisco river basin (Brazil) using remote sensing and Penman-Monteith equation. Remote Sens. 2: 1287-1319.

Teixeira, A. H. de C. 2012a. Modelling evapotranspiration by remote sensing parameters and agrometeorological stations. In Remote Sensing and Hydrology (C. M. U. Neale and M. H. Cosh, Eds.), vol. 352. IAHS Press, Oxford, pp. 154-157.

Teixeira, A. H. de C. 2012b. Determination of surface resistance to evapotranspiration by remote sensing parameters in the semi-arid region of Brazil for land-use change analyses. In Remote Sensing and Hydrology (C. M. U. Neale and M. H. Cosh, Eds.), vol. 352. IAHS Press, Oxford, pp. 167-170.

Teixeira, A. H. de C., W. G. M. Bastiaanssen, M. D. Ahmad, and M. G. Bos. 2008. Analysis of energy fluxes and vegetation-atmosphere parameters in irrigated and natural ecosystems of semi-arid Brazil. J. Hydrol. 362: 110-127.

Teixeira, A. H. de C., W. G. M. Bastiaanssen, M. D. Ahmad, and M. G. Bos. 2009a. Reviewing SEBAL input parameters for assessing evapotranspiration and water productivity for the Low-Middle São Francisco River basin, Brazil Part A: Calibration and validation. Agric. For. Meteorol. 149: $462-476$.

Teixeira, A. H. de C., W. G. M. Bastiaanssen, M. D. Ahmad, and M. G. Bos. 2009b. Reviewing SEBAL input parameters for assessing evapotranspiration and water productivity for the Low-Middle São Francisco River basin, Brazil Part B: Application to the large scale. Agric. For. Meteorol. 149: 477-490.

Troufleau, D., J.-P. Lhomme, B. Monteny, and A. Vidal. 1997. Sensible heat flux and radiometric surface temperature over sparse sahelian vegetation: Is the $\mathrm{kB}^{-1}$ a relevant parameter? J. Hydrol. 189: 815-838.

Valiente, J. A., M. Nunez, E. Lopez-Baeza, and J. F. Moreno. 1995. Narrow-band to broad-band conversion for Meteosat visible channel and broad-band albedo using both AVHRR-1 and -2 channels. Int. J. Remote Sens. 16: 1147-1166. 
